\title{
Conclusions and Recommendations: Between Unwillingness and Willingness to Defend Own Country in the Baltic States and Beyond
}

\author{
Dr. Māris Andžāns (ORCID: 0000-0002-4695-3929),
} Rīga Stradiňš University and Latvian Institute of International Affairs

https://doi.org/10.25143/willingness_to_defend_2021_ISBN_9789934563997_78-80

The reasons for willing or not willing to defend own country are many and usually case specific. They include but are not limited to the (lack) of patriotism and national pride, (dis)trust in state institutions and politicians, economic situation and (in)equality, historical grievances and past victories, religious and cultural affiliations, education level, gender, ethnicity, political and ideological affiliations, an d mi li tary re cr uitment mo de ls. The le vel of willingness also depends on the nature of a (potential) conflict that the society in question is about to face - either one of necessity, or as a choice; the former relates to self-defence against immediate threats while the latter to more distant threats. These aspects were in detail deliberated in the first two chapters by the author of these lines, as well as Dr. Yao-Yuan Yeh.

The level of willingness to defend own country is usually assessed with the help of sociological polls. Plenty of them have been conducted in the Baltic states. Most of such polls have been organized in Estonia. The least data are available for Lithuania. While the methodological approaches and questions in such surveys tend to vary, they nevertheless demonstrate some consistent trends. Most notably, the level of willingness to defend Estonia is the highest. Latvia and Lithuania trail their northern neighbour, as further discussed in the chapter "Willingness to Defend the Baltic States in Quantitative Terms".

Reasons for the current situation in the Baltics are multiple and complex. Authors of this publication provided their explanations. For Estonia, which 
excels not only via a rich pool of data, but also by demonstrating the highest willingness level, Dr. Ivo Juurvee puts forth several points. While such factors as historical experience, i.e., the Soviet occupation and visibility of NATO Allies, are shared with both Latvia and Lithuania, other reasons are more Estonia-specific. Among these are the effective integration of military and civilian sector, i.e., a mature conscription system, operational reservists' system, and effective military-civilian communication. Another positive factor is the Nordic, or more specifically Finnish, influence on the Estonian military culture, as well as the governance approach and lifestyle in broader terms (as the second chapter of this publication notes, Nordic societies have traditionally espoused high levels of willingness to defend own country). Nevertheless, a notable issue remains - level of willingness is lower among non-Estonians, i.e., Russian speakers.

In Latvia, the willingness level is lower than in Estonia but higher than in Lithuania. That level is neither high nor low in a regional and global context. Aleksandra Palkova in her chapter names the main categories of reasons that affect the situation. First, a set of detrimental factors - disillusionment with political and economic development and the related widespread distrust in state institutions and politicians. Second is a mixed factor \& actor - Russia. Its military conflict with Ukraine, assertive behaviour and negative rhetoric towards Latvia have made a considerable part of the Latvian society feel insecure, whereas another part of the society, mostly Russian speakers, remain more sympathetic to Russia. Third is an impeding mix of physiological and physical factors - complacency resulting from the lack of recent experience of notable conflicts and the lack of military training of most people.

For Lithuania, Dr. Ieva Gajauskaitè suggests taking extra care in interpreting the scarce data available on Lithuania. Nevertheless, she observes that issues with willingness to defend Lithuania exist. She underlines patriotism, pride in the state, as well as specific skills, i.e., military experience, and active civil society as the main preconditions for willingness to defend own country. To a various degree, in all those aspects space for progress in Lithuania remains. Attitude towards the state is a broad and complex issue to address. While conscription was reintroduced in Lithuania in 2015, its effect on willingness to defend Lithuania has not yet reached its full potential. Space for progress in societal attitudes is 
acknowledged also by the Lithuanian authorities, which treat it primarily in the context of civil resistance.

The analyses presented in this book, as well as in other similar studies should draw the attention not only of policy makers in the Baltic states but also in other NATO member states and beyond. Professional soldiers, conscripts and (paramilitary) volunteers are part of the society. Mood dominant in the society can have impact on their resolve and determination to fight. Furthermore, since patterns of modern conflicts have evolved, societies increasingly have become subjected to competing narratives. States, at least in the West, have no monopoly over the main channels and narratives of information.

That said, the role of societies and collective and individual willingness to defend own country today is even more paramount. While such issues are primarily a national responsibility, the concept of resilience in NATO has received growing attention. Nevertheless, NATO collectively and its member states individually should pay more attention to the societal factors. Institutions of some member states, including Latvia and Lithuania, should better comprehend the situation in their societies and should seek a more subtle balance between slogans and reality about the determination of their inhabitants to fight and resist if it came to that. The situation with the Covid-19 vaccination rates and the underlying distrust in state institutions \& their messages serve as yet another indicator that there is space for progress. Or else, in an unlikely situation of armed confrontation, support from the members of society can disappoint.

As to how to strive for higher levels of willingness to defend own country, there is no one single formula. Estonia's example and lessons from its experience might be a good start for both its southern neighbours. Meanwhile, both Estonia and Latvia should continue working towards integrated societies. That is, however, a complex mix of issues. Finally, the margin between desirable and undesirable methods in enhancing the willingness level is subtle. Ideally, members of a society should genuinely share the view that their country is worth defending, not merely be indoctrinated that the country must be defended. 